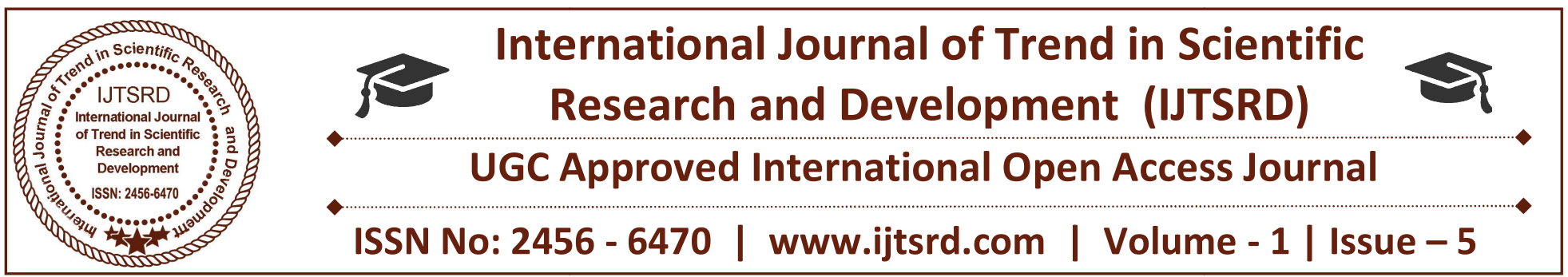

\title{
Evaluation of the Process of Attention using the Simulation of Processes
}

\author{
Muñoz Martiñon Rodolfo \\ Universidad de la República \\ Mexicana, Mexico
}

\author{
Robles Ramírez Diana P. \\ Universidad Insurgentes, Mexico
}

\author{
Vanessa Zamudio Hidalgo \\ Universidad de la República \\ Mexicana, México
}

\begin{abstract}
The present work aims to perform an evaluation of the customer service process in the service area, for which a study using a reliability of $90 \%$ with the process simulation technique was carried out. A descriptive - analytical methodology was developed with a sample of 68 time points for each area of the care process. The results obtained helped to measure the productivity of the service process, resulting in a productivity of $89.31 \%$.
\end{abstract}

Keywords - Process of attention, productivity and simulation of processes

\section{INTRODUCTION}

Computer simulation developed at the same time as the vertiginous progress of the computer took place. Its first large-scale deployment was in the Manhattan Project during World War II, to recreate a nuclear detonation. The Monte Carlo method was used. Computer simulations sometimes supplement or even replace modeling systems for which it is not possible to find analytical solutions in a closed fashion. There are many types of computer simulation, but they all share one common feature: they try to generate a sample of representative scenarios for a model in which a complete relation of all possible states of this would be very costly or impossible. Computerized models were initially used as a supplement to other parameters, but later their use was extended to other areas (Frank, 2011).

Aponte (2011) The simulation is to recreate a system or imitate a reality that looks so much like it without needing to be it in order to estimate what their real performance would be, this involves deception, trap and in nature a case of deception is seen In the chameleon since it is an animal that is characterized by adopting different colors.

The simulation of a productive process is the copy of the dynamic system of the process in a model, the objective is the obtaining of knowledge to transfer them to the reality (EnpresaDigitala, 2003).

A simulation language is simulation software of a general nature and has some special features for certain applications, such as SLAM 11 and SIMAN (simulation software) with its manufacturing modules. The model is developed using the appropriate language instructions and allows the analyst a great control for any kind of system (Salazar, s / f).

Vatic Group (2013) Simulation provides you with excellent ways to communicate your ideas through:

Provide a graphical representation of the system studied

$>$ Incorporating 3D animations that allow you to visualize the process. This allows a greater understanding of the challenges and characteristics of the operation

Animation that allows the directives to understand the proposed changes and simplifies the work of selling the internal projects to the directives

> Simulation also provides a tool to educate operators and supervisors in the way the system will operate. Aspects such as administration, shifts and maintenance and operation strategies can be 
explored with a better understanding of the complex interactions that exist between system processes. Simulation provides a method for learning how to use problem solving techniques.

The origins of ProModel go back to when Harrell worked as a Production Engineer at Ford Motor Company in 1976. The challenge was to determine the right balance between machine capabilities, buffering, and resource allocation to meet production levels Defined for each production line (Harrell, s / f).

\section{GENERAL OBJECTIVE}

Evaluate the care process using the process simulation technique.

\section{SPECIFIC OBJECTIVES}

$>$ Know the process of study attention.

$>$ Understand the hierarchy of the care process.

$>$ Apply the simulation technique for the care process.

$>$ Simulate the care process using specialized software

$>$ Analyze the productivity of the care process.

$>$ Evaluate the results obtained from the analysis of the productivity of the care process.

\section{JUSTIFICACIÓN}

Many service industries have a queuing system, where products or customers arrive at a station and wait in a row, get some kind of service, and then leave the system (Kamlesh and Solow, 1996). Gross and Harris (1998) mention that queuing theory is the study of such waiting in its different forms, using queue models represent queue systems that arise in practice. The formulas for each model indicate what the corresponding system should perform and indicate the expected amount of time and people in a queue, in a range of circumstances. A waiting line is constituted by a client that requires a service that is provided by a server in a certain period. Customers randomly enter the system and form one or more queues to be serviced. If the server is unoccupied, according to certain rules pre-established with the service discipline name, the service is provided to the queue elements in a certain period of time, called service time and then leave the system (Escudero,1972).

Vaughn (1993) mentions the need in organizations to analyze, know and explore their care systems where they generate waiting lines, in order to reduce the impact they have on their productivity. Queue networks and the broader view of systems, together with the greater approximation of non-exponential distributions and new solution methodologies, are variations that make this study very useful to the services sector, approaching more and more their actual situation. Vaughn (1993) points out that the study of the multidisciplinary approach of industrial engineering has made technological, organizational, commercial, economic, financial and operational aspects indispensable to achieving profitability and productivity, as the pillar of this area.

\section{METHODOLOGY}

The steps that were followed to develop the project were those proposed by García, García and Cárdenas. (2006).

Definition of the system. In this phase it is necessary to know the system to be simulated. For this, random visits were made to the care process. He tried to be a very good observer.

Generation of the base simulation model. Once the system to be studied is known, a simulation base model must be developed. In this phase, the preliminary model of the care process was carried out. Figure 1 shows the sketch of the model.

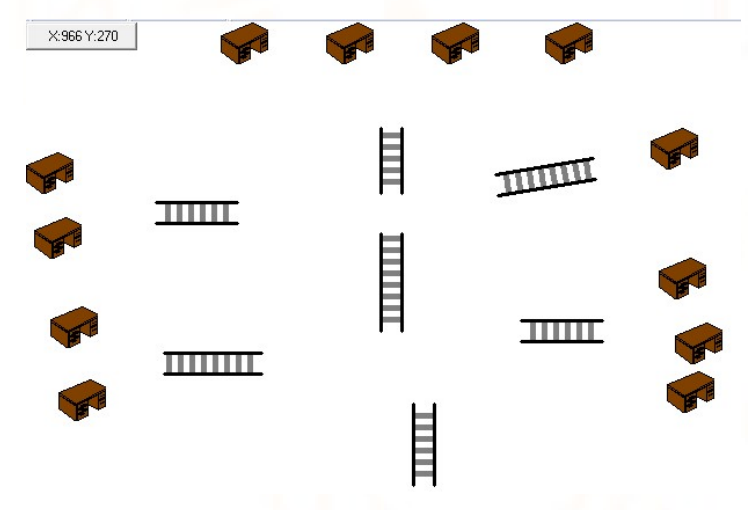

Figure 1: Example of preliminary model

Collection and analysis of data. It is suggested to start with the collection of the statistical information of the variables of the model. Each process is monitored to find the average time it takes each activity. The formula proposed by Salas (s / f) was used to know how many time samples should be made.

$$
n=\frac{Z^{2} * p[1-p]}{E^{2}}
$$


Where:

$\mathrm{N}=$ is the number of times taken to develop.

$\mathrm{Z}=$ is the confidence interval to be used. For this project $90 \%$ reliability was used.

$\mathrm{P}=$ is the probability of success. For this project was used a 0.5 of success.

$\mathrm{E}=$ is the percentage of error allowed. For this project $10 \%$ was used.

$$
n=\frac{(1.645)^{2} * 0.5[1-0.5]}{(0.10)^{2}}=\frac{0.6765}{0.01}=67.65=68
$$

For the present project, using 90\% reliability, 10\% error, a probability of success of $0.5,68$ times were made for each process.

Generation of the preliminary model. At this stage, the information obtained from the analysis of the data, the model assumptions and all the data required to have a model that is closest to the reality of the problem under study is integrated. Figure 2 shows an example of the model already with the calculated times.

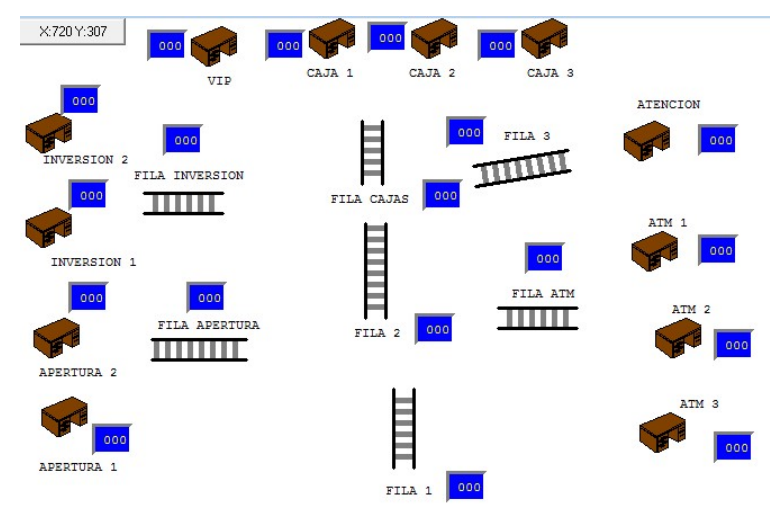

Figure 2: Example of model with calculated.

Verification of the model. It is suggested to verify the data collected in the previous stages, to prevent errors in the model. For this stage, we re-reviewed the calculated results obtained with the results. If any errors are found, the changes are made at this stage.

Validation of the model. In this phase is to perform a series of tests, using real input information to observe their behavior and analyze their results. For this stage, 30 pilot tests were performed, in order to observe the behavior of the model. For the study model, the pilot tests were acceptable and nothing abnormal was found in its operation.
Generation of the final model. Once the model has been validated, the model is ready to be simulated and studied. At this stage, we used the formula proposed by Diaz (1995) who proposes a formula to know the number of runs to simulate a process, in this case, the process of attention.

The formula used was as follows:

$$
T=\frac{t_{\frac{\alpha}{2}}^{2} p_{h}(1-P h)}{A^{2}}
$$

Where:

$\mathrm{T}=$ is the number of replications,

$\mathrm{Ph}=$ is the default imprecision level $\mathrm{A}$

$1-=$ is the confidence level

For this investigation it was calculated with a confidence interval of $99 \%$, using a right tail of probability of 0.05 and a level of imprecision of 0.05 . The theoretical probability of the interval according to the author is in a range $(0.045-0.055)$. The formula will be as follows:

$$
T=\frac{t_{\frac{\alpha}{2}}^{2} p_{h}(1-P h)}{A^{2}}=\frac{(2.57)^{2} * 0.05 *(1-0.05)}{(0.05)^{2}}=\frac{0.3136}{0.0025}=125.44 \approx 126
$$

The result shows that for a reliability of $99 \%$ and an imprecision of 0.05 , the care process was simulated 126 times.

Determination of the scenarios for the analysis. It is suggested to use possible solution scenarios for the process studied. In this phase, possible solution alternatives were observed so that the care process has a competitive productivity.

Documentation of the model, suggestions and conclusions. Once the analysis of the results has been performed, it is necessary to carry out all the documentation of the model. At this stage all the steps of the project and their calculated calculations were recorded. 


\section{ANALYSIS OF RESULTS}

At this stage the calculation of the productivity of the care process was performed, for which the results of ProModel ${ }^{\circledR}$ specialized software were reviewed. Table 1 shows an example of the calculated values obtained.

Table 1: Example of results

\begin{tabular}{|c|c|}
\hline Variable & Total \\
\hline ClientsServed & 376 \\
\hline Clientsin queue & 19 \\
\hline FailedCustomers & 26 \\
\hline Total & 421 \\
\hline & \\
\hline Productivity & 89.31 \\
\hline
\end{tabular}

The table above represents the productivity of the care process, which is good, but has areas of opportunity, since 45 clients are stopped, which represents $10.69 \%$ productivity.

Figure 3 represents an example of the percentage of utilization of the work areas

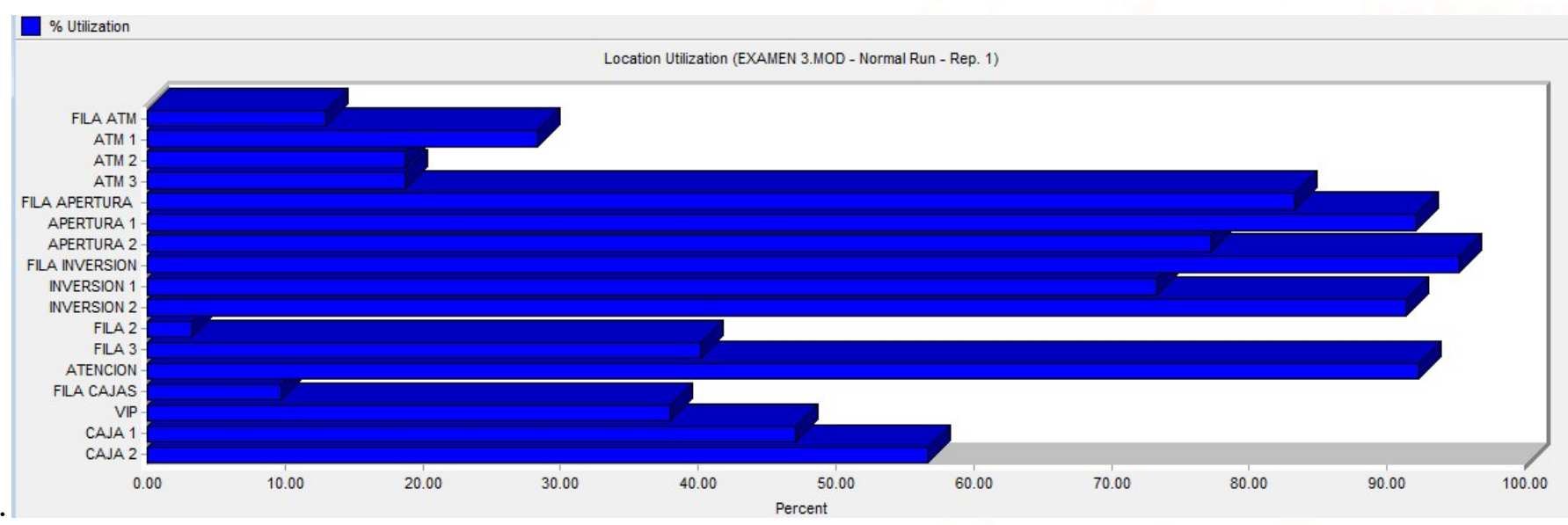

Figure 3: Example of percentage of use of work areas.

The previous figure shows how the work areas do not work in a similar way, which means that productivity is $89.31 \%$.

\section{CONCLUSIONS}

The project was successfully concluded, obtaining the evaluation of the care process. Productivity was obtained, which is good but not competitive.

Likewise, it was possible to know the process of study attention. It was also possible to understand the hierarchy of the attention process. It was possible to apply the simulation technique for the care process. It was able to simulate the process of attention using specialized software. In addition, it was possible to analyze the productivity of the care process.

\section{ACKNOWLEDGMENT}

M.I.I. Arturo González Torres for his advice, mentoring and project management.

\section{REFERENCES}

1) Aponte, D. (2011). Introducción al concepto de simulación.

2) Díaz Emparanza, I. (1995). Selección del número de replicaciones en un estudio de simulación. Departamento de Econometría y Estadística. 
Universidad del País Vasco - 8) Harrell,C. (s/f). LosiniciosdeProModel. ProModel EuskalHerrikoUnibertsitatea. Corporation.

3) EnpresaDigitala. (2003). Simulación de Procesos Productivos. EnpresaDigitala

4) Escudero, L. F. (1972). Aplicaciones de la teoría de colas: análisis y solución de los problemas de cuellos de botellas en almacén, producción y ventas con referencias breves a Business Games y teoría de juegos. Primera edición. Bilbao: Deusto.

5) Frank. (2011). Breve Historia de la Simulación. Simulalo.

6) García Dunna, E., García Reyes, H. y Cardenas Barrón, L. E. (2006). Simulación y análisis de sistemas con ProModel®. Pearson Prentice Hall.

7) Gross y Harris. Fundamentals of queueingtheory. Tercera edición. New York; Chichester: John Wiley, 1998. p. 20-34.

9) Kamlesh y Solow. (1996). Investigación de operaciones: el arte de la toma de decisiones. Primera edición. México; New York: PrenticeHall Hispanoamericana, 1996. p. $710-711$.

10) Harrell, C. (s/f). Los inicios de ProModel. ProModel Corporation.

11) Salas Bacalla, J. (s/f). Muestreo de Trabajo. Biblioteca Central Pedro Zulen. Universidad Nacional Mayor de San Marcos.

12) Salazar Guerrero, A. (s/f). Simulación de eventos. Centro Cultural Itaca S. C.

13) Vaughn, R. C. (1993). Introducción a la ingeniería industrial. Segunda edición. Barcelona: revert. p. 30-32.

14) VaticGroup. (2013) ¿Por qué simular?- Cuándo y qué ventajas tiene simular. VaticGroup. 